\title{
Odontologia do esporte: revisão de literatura
}

\author{
Sportive dentistry: literature review \\ Odontología del deporte: revisión de literatura \\ Ana Caroline Alayon LIMA \\ Ellen Luíze de Oliveira CARDOSO \\ Paulo Roberto Lopes FERREIRA JUNIOR \\ Gabriela BENTO \\ Marcela Filié HADDAD
}

Departamento de Odontologia Restauradora e Prótese. Faculdade de Odontologia, UNIFAL-MG Universidade Federal de Alfenas, 37.130-000 Alfenas - MG, Brasil

\section{Resumo}

Introdução: A Odontologia do Esporte vem ganhando espaço e se tornando mais conhecida; mostrando que assim como a medicina, a nutrição e a fisioterapia, ela também possui sua importância no desempenho do atleta. Objetivo: Realizar uma revisão de literatura fazendo uma reflexão sobre a relação do desempenho do atleta com a manutenção da saúde bucal e o papel do cirurgião dentista nesse cenário. Material e Método: A pesquisa bibliográfica foi realizada utilizando as bases de dados Scielo, Lilacs, Pubmed e Teses USP. Resultados: A presente revisão aborda os tópicos: Odontologia do esporte; seu reconhecimento com especialidade e áreas de atuação; traumatismos; protetores bucais e faciais; desordens odontológicas com impacto na prática do esporte; doping e Odontologia. Conclusão: É necessária maior divulgação e conscientização sobre a importância da especialidade de Odontologia do esporte, do uso de protetores bucais personalizados e do quanto que um foco infeccioso e/ou oclusão deficiente podem influenciar no desempenho do esportista.

Descritores: Protetores Bucais; Traumatismos Dentários; Traumatismos em Atletas.

\begin{abstract}
Introduction: Sportive Dentistry has been gaining space and becoming better known; showing that just like medicine, nutrition and physiotherapy, it also has its importance in the performance of the athlete. Objective: Presents a literature review with a reflection on the relationship between the performance of the athlete and the maintenance of oral health and the role of the dental surgeon in this scenario. Material and Method: The literature search was performed using the Scielo, Lilacs, Pubmed and USP Theses databases. Results: The present review addresses the following topics: Sportive Dentistry; specialty recognition and areas of practice; injuries; mouth and facial protectors; dental disorders with impact on sports practice; doping and Dentistry. Conclusion: Greater dissemination and awareness about the importance of the specialty of Sports Dentistry, the use of personalized mouth guards, and the fact that an infectious focus and / or poor occlusion may influence the performance of the athlete is necessary.
\end{abstract}

Descriptors: Mouth Protectors; Tooth Injuries; Athletic Injuries.

\section{Resumen}

Introducción: La Odontología del Deporte viene ganando espacio y haciéndose más conocida; que muestra que así como la medicina, la nutrición y la fisioterapia, ella también tiene su importancia en el desempeño del atleta. Objetivo: Realizar una revisión de literatura haciendo una reflexión sobre la relación del desempeño del atleta con el mantenimiento de la salud bucal y el papel del cirujano dentista en ese escenario. Material y Método: La investigación bibliográfica fue realizada utilizando las bases de datos Scielo, Lilacs, Pubmed y Tesis USP. Resultados: La presente revisión aborda los tópicos: Odontología del deporte; su reconocimiento con especialidad y áreas de actuación; traumatismos; protectores bucales y faciales; desordenes odontológicos con impacto en la práctica del deporte; dopaje y Odontología. Conclusión: Es necesaria mayor divulgación y concientización sobre la importancia de la especialidad de Odontología del deporte, del uso de protectores bucales personalizados y de cuánto un foco infeccioso y / o oclusión deficiente pueden influenciar en el desempeño del deportista.

Descriptors: Protectores Bucales; Traumatismos de los Dientes; Traumatismos en Atletas.

\section{INTRODUÇÃO}

Odontologia é a ciência cuja abrangência direta é a saúde bucal, imprescindível para que os indivíduos possam comunicar-se, mastigar, deglutir e pelo fator estético que influencia na autoestima e nas relações sociais do sujeito ${ }^{1}$. A manutenção da saúde bucal é fundamental na prática esportiva, a qual vem sendo largamente difundida nos dias atuais devido aos benefícios que propicia à saúde e por promover melhora estética ${ }^{2}$.

Contudo, o esporte traz consigo o espírito competitivo e vale considerar que a manutenção da saúde é um fator de suma importância para o desempenho do atleta e a saúde bucal é fundamental nesse processo ${ }^{1}$. Desse modo, a Odontologia do esporte vem ganhando espaço e se tornando mais conhecida; mostrando que assim como a medicina, a nutrição e a fisioterapia, ela também possui sua importância nesse âmbito ${ }^{2}$.

Antigamente, a Odontologia do esporte restringia-se ao uso de protetores bucais para que traumas fossem evitados. Hoje é muito mais abrangente, focada na promoção de saúde e aumento do rendimento do atleta $^{3}$, atuando na prevenção e eliminação dos problemas bucais como cárie, doença periodontal, abscessos, má oclusão, hábitos viciosos, respiração bucal, desordens na articulação temporomandibular e traumatismos. Ou seja, possui enfoque multidisciplinar abordando muitas especialidades odontológicas em conjunto com a atuação de outros profissionais, repercutindo diretamente sobre a saúde bucal e, consequentemente, saúde geral do atleta, afetando seu rendimento e desempenho ${ }^{2}$.

Assim, o objetivo do presente estudo é apresentar uma revisão de literatura sobre a Odontologia do esporte, abordando sua definição, importância e impacto que exerce sobre seu público alvo.

\section{MATERIAL E MÉTODO}

Nas bases de dados Google Acadêmico, Scielo, Lilacs, PubMed e Teses USP foram pesquisados os seguintes termos: "odontologia do esporte", "traumatismo em atletas", "protetores 
bucais", "odontologia no esporte", "doping no esporte", "traumatismos dentários" e "odontologia neurofisiológica".

Como critério de inclusão, foram adotados os seguintes parâmetros: artigos em Língua Portuguesa e inglesa, publicados entre os anos 1999 e 2016, que abordassem relatos clínicos, pesquisas laboratoriais e de opinião, estudos sobre tipos de protetores bucais e revisões de literatura. Foram excluídos artigos escritos em idioma diferente do português e inglês, artigos repetidos e que apresentaram fuga do tema. Dessa maneira, 1 trabalho de conclusão de curso, 1 monografia, 2 dissertações, 1 tese, 1 livro, 6 sites e 18 artigos foram selecionados para compor esta revisão.

\section{RESULTADOS}

\section{- Odontologia do Esporte}

Existem vários fatores importantes no rendimento competitivo, entre eles o fator genético, elementos fisiológicos, psicológicos e treinamento. Qualquer desequilíbrio entre esses fatores causa danos ao desempenho do atleta. Dentre os elementos fisiológicos pode-se citar a saúde bucal, que pode interferir negativamente quando em déficit ${ }^{4}$.

A Odontologia é a ciência que visa à manutenção da saúde do sistema estomatognático ${ }^{5}$. Já a odontologia do esporte é uma nova área, que busca desenvolver e manter condições físicas ideais dos atletas $^{6}$, detectando mudanças na cavidade oral que podem comprometer o rendimento do indivíduo ${ }^{7}$.

A Odontologia do esporte envolve a prevenção e o tratamento de injúrias orofaciais, doenças e alterações orais relacionadas a atletas ${ }^{2}$. É uma área multidisciplinar que contribui no diagnóstico de problemas bucais com repercussões sistêmicas, norteando atletas e interessados sobre a necessidade de sua ampliação ${ }^{8}$.

Nesse ramo da Odontologia, odontólogos e educadores físicos unem-se para estudar os benefícios proporcionados aos atletas que se submetem a tratamento odontológico a fim de melhorar seu desempenho através da prevenção, manutenção da saúde bucal e tratamento de possíveis lesões na cavidade bucal decorrentes de práticas esportivas ${ }^{9}$.

Uma equipe multidisciplinar de apoio ao atleta garante melhor rendimento competitivo, visto que problemas na saúde bucal podem ser fontes de dores e infecções podendo atrapalhar os resultados de um competidor. Para que o fim da carreira de um atleta não seja concretizado é preciso se submeter a exames simples e rotineiros de prevenção ${ }^{9}$.

- Reconhecimento como especialidade e áreas de atuação

No dia 2 de outubro de 2015 o Conselho Federal de Odontologia por meio da Resolução de número 160 reconhece a Odontologia do Esporte como especialidade. É notório que a função do cirurgião-dentista no âmbito esportivo é direcionada para prevenção e orientações sobre saúde, e não meramente curativa em momentos pós-lesão ${ }^{1}$.

O cirurgião-dentista do esporte tem como função fazer avaliações da saúde bucal do atleta nos períodos pré-contratual, pré-participação e pósparticipação; proporcionar atendimento inicial no local dos eventos, treinos e jogos, atuar nos episódios de acidentes orofaciais; administrar adequadamente substâncias e medicamentos, desprezando os que podem acarretar doping ao atleta; desenvolver trabalhos com uma equipe multidisciplinar proporcionando campanhas de prevenção de saúde bucal, provendo informações a respeito de procedimentos de urgência e utilização de equipamentos de proteção adequados para cada modalidade esportiva ${ }^{10}$.

Além disso, deve conhecer os protocolos de atendimento médico adequados a serem executados previamente ao tratamento dentário; assistir treinos e competições; respeitar os direitos desportivos do atleta e sua imagem; ter conhecimento de como o esporte pode ser um instrumento para o marketing estratégico da Odontologia; empregar métodos, tecnologias e produtos capazes de treinar, informar, analisar, alimentar e reabilitar atletas de alto rendimento; executar a Odontologia Neurofisiológica, a qual consiste em abordar todo o sistema corporal que comanda a postura e atividade da mandíbula e busca determinar uma posição agradável aos músculos, dentes e articulações temporomandibulares ${ }^{10,11}$.

\section{- Traumatismos}

Podem ser considerados problemas de saúde pública: traumatismo dental, cárie, doença periodontal e câncer bucal. Eles afetam a integridade física e psicológica do indivíduo, sendo relevantes na sua qualidade de vida ${ }^{12}$. A prática esportiva é considerada um importante fator etiológico quando se trata de injúrias orofaciais, foco de atuação preventiva na prática odontológica ${ }^{13}$.

Com a crescente prática esportiva, principalmente dos esportes de contato e radicais, há enorme disposição para o aumento dos índices de traumatismos dentários e faciais devido à ausência ou escassez de proteção destas regiões e a falta de orientações sobre a importância da prevenção para proteger estas áreas ${ }^{14}$.

Traumas faciais podem acontecer de forma isolada ou concomitante com outros traumas (craniano, cervical, membros) e podem ocasionar deformidades permanentes, implicar no emocional e na funcionalidade. Sua etiologia é diversa e relaciona-se com idade, sexo, classe social e localização da sociedade analisada ${ }^{14}$.

A prevenção se faz com auxílio de protetores durante a prática esportiva. Esses têm como função 
proteger os tecidos duros e moles da boca e da face 13 e podem ser divididos em intraorais e extraorais. Protetores intraorais ou bucais são colocados no espaço interdental. Protetores extraorais ou faciais/nasais estão relacionados ao capacete ou cabeça do atleta ${ }^{15}$.

\section{- Protetores Bucais}

$\mathrm{O}$ uso dos protetores bucais diminui em até $80 \%$ a ameaça de trauma dental. Todo atleta envolvido em um esporte de contato tem $10 \%$ de chance de sofrer um acidente dental ou oral. Se não estiver fazendo uso do protetor bucal o risco de sofrer um ferimento dental aumenta mais de 60 vezes. $\mathrm{O}$ protetor bucal quando bem ajustado e adaptado não interfere na respiração do atleta, podendo o mesmo falar e ingerir líquidos sem removê-lo da boca ${ }^{5}$.

Estes protetores são confeccionados geralmente para a arcada superior, devido ao fato de a região anterior superior ser a de maior propensão a trauma. Os mesmos são fabricados com diferentes materiais como etileno-vinil-acetato (EVA), silicone, plástico, borracha e podem ser de vários

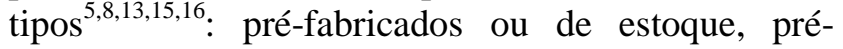
fabricados termoplásticos, personalizados e bimaxilares.

Os protetores bucais pré-fabricados ou de estoque são adquiridos em lojas de produtos esportivos e já vem pronto para o uso. Este tipo de protetor não possui boa adaptação, sendo mantido no lugar pela pressão dos dentes em oclusão; interfere na fala e respiração do atleta.

Os protetores bucais pré-fabricados termoplásticos, também adquiridos em casas de materiais esportivos, não vêm prontos para uso. $\mathrm{O}$ atleta deve aquecer o dispositivo em fervura e morder. Durante o uso, tem que permanecer de boca fechada para que o protetor não caia, pois o mesmo não apresenta boa retenção, uma vez que é plastificado em água aquecida e adaptado aos dentes e mucosa pelo atleta, sem orientação profissional.

Confeccionado em consultório, a partir da moldagem da arcada do atleta e obtenção de modelo, o protetor bucal personalizado tem melhor adaptação e retenção que os demais e pode ser confeccionado com diferentes materiais de acordo com a necessidade. É o tipo ideal para portadores de aparelhos ortodônticos fixos, necessitando de um pequeno alívio com cera utilidade no momento da moldagem Para a confecção deste protetor são necessárias visitas ao consultório odontológico, portanto seu custo é maior ${ }^{5,6,13,15}$.

$\mathrm{O}$ protetor bimaxilar é modelado na boca (termoplástico) e recobre os dois arcos dentários ao mesmo tempo. A mandíbula é fixada em uma posição predeterminada que possibilite a respiração máxima e relaxada, permitindo uma ventilação apropriada. Este tipo de protetor faz com que a cabeça do côndilo rotacione no interior da cavidade glenoide, diminuindo a transmissão de forças à mesma e ao crânio, protegendo o esportista de lesões no côndilo e de lesões por concussões, protegendo também os dentes inferiores dos traumas ${ }^{16}$.

Estes aparelhos tem duração média de um ano. Em crianças e adolescentes, devido à fase de crescimento ósseo, e quando o atleta apresentar grandes variações de peso devem ser trocados com regularidade. $\mathrm{O}$ atleta deve estar informado da importância do uso dos protetores bucais e que esses devem ser usados desde os treinos até as competições $^{5}$, pois, quando a prática esportiva acontece com a utilização de protetores, os riscos de lesões diminuem ou são evitados. Contudo, a maioria das universidades e centros esportivos brasileiros ignoram a Odontologia voltada ao esporte ${ }^{13}$.

Nos Estados Unidos é obrigatório o uso de protetores bucais em modalidades mais violentas há mais de três décadas. Já no Brasil essa prevenção não é adotada e acidentes que envolvem lesões maxilofaciais nem entram nas estatísticas. Eles são importantes, pois oferecem amortecimento na hora do impacto e distribuem as forças, evitando fraturas e avulsões dentais. Além disso, os protetores bucais protegem não só os dentes e os tecidos moles, mas também a cabeça e o pescoço, podendo evitar até a morte $^{17}$.

Com o objetivo de investigar a prevalência de traumatismos dentários na população praticante de dois esportes de contato (Judô e Taekwondô), e caracterizar alguns fatores associados, Lopes e Ferreira $^{18}$ realizaram estudo piloto transversal com caráter observacional para registro de dados e informações. A amostra foi composta por 60 indivíduos com idades de 5 a 15 anos, de ambos os sexos, praticantes de Judô ou Taekwondô no Parque dos Jogos $1^{\circ}$ de Maio- INATEL. Foi aplicada estatística descritiva e inferencial para a análise dos resultados. A prevalência de traumatismos dentários na população em estudo foi de $38,3 \%$, em que a maioria ocorreu fora da prática esportiva $(82,6 \%)$. Apenas 4 crianças sofreram traumatismos durante a prática esportiva, correspondendo a uma prevalência de 6,67\%. O único esporte predisponente para o trauma neste estudo foi o Judô. Os dentes mais atingidos foram os incisivos centrais superiores decíduos e permanentes, a maioria das situações afetou apenas um dente. O lábio foi o tecido mole com maior número de lesões traumáticas. $\mathrm{O}$ hábito de utilização de protetor bucal teve frequência nula. Verificou-se relação estatisticamente significativa entre a ocorrência de trauma e os fatores de risco estudados ${ }^{18}$.

\section{- Protetores faciais / nasais}

É notado aumento expressivo das fraturas nasais durante páticas esportivas nos últimos 15 anos devido ao acréscimo de esportes em ambiente fechado, sendo o osso nasal um dos mais atingidos 
(56\% aproximadamente) sendo que $15 \%$ destas fraturas são recorrentes ${ }^{19}$.

Uma das maneiras de prevenção e auxílio durante a recuperação dessas fraturas é o uso de protetores. Esses evitam que, durante um impacto, o osso em processo de reparação seja deslocado ou sofra refratura, além de atuar de forma preventiva em modalidades de alto risco ${ }^{20}$.

Uma fratura nasal deve afastar o atleta de sua prática esportiva por até dez dias e demanda o uso de protetor nasal para esporte durante pelo menos 30 dias, período médio para a consolidação da fratura ${ }^{19}$.

A conformação do protetor e os pontos de retenção na face devem proporcionar conforto para 0 esportista e o material utilizado na sua confecção deve apresentar boa capacidade amortecedora ${ }^{21}$. Vários materiais podem ser utilizados, mas o mais comumente empregado é o EVA, por apresentar conformação a baixa temperatura, fácil manipulação, transparência; baixo custo; moldabilidade; durabilidade; facilidade de acabamento; auxiliar na absorção de energia e amortizar a transmissão de impacto $^{21}$. O polimetilmetacrilato (PMMA) também pode ser empregado. Neste caso, o protetor deve ser revestido com material reembasador/condicionador de tecido extramacio ${ }^{22}$. O PMMA é amplamente utilizado na confecção de próteses por ser barato; de fácil modelagem; possuir alta resistência mecânica e ao impacto e ser de fácil pigmentação ${ }^{23}$.

O protetor facial parcial possui cerca de 4 milímetros de espessura, é leve e confortável; prendese a face com elásticos ou bandas que, segundo atletas, não incomodam durante a prática esportiva e permitem uma visão periférica desobstruída ${ }^{22}$.

\section{- Desordens odontológicas}

$\mathrm{O}$ rendimento físico de um atleta pode ser reduzido em $21 \%$ se ele apresentar algum distúrbio na cavidade bucal $^{24}$. Primeiramente, o cirurgião dentista deve eliminar os focos infecciosos da cavidade bucal do atleta. Cáries, doenças periodontais, gengivites e raízes residuais são focos de infecção e devem ser eliminadas, pois atrapalham a mastigação e a respiração, interferindo também no rendimento físico ${ }^{3}$.

A respiração bucal é citada como grande influenciadora no desempenho de atletas já que tem consequências diretas na respiração, estrutura óssea, arcada dentária, sono, aprendizagem, audição, dicção, paladar, fonação e olfato ${ }^{4}$. A síndrome do respirador bucal pode ser resultante de fatores intrínsecos e extrínsecos ao nariz, tais como: hipertrofia de amígdalas, infecções repetitivas das vias superiores, rinites crônicas (alérgica, infecciosa, por drogas, hormonal e idiopática), sinusites, obstrução nasal por iatrogenia (pós cirurgia e medicamentosa), por irritantes, tonsilite crônica hipertrófica, desvio septal, massas nasais (pólipos, corpos estranhos, tumores), fossas nasais estreitas, hábito residual ou de manter a boca aberta e posição de dormir ${ }^{4}$.

É percebida em respiradores bucais a falta de ar ou insuficiência respiratória, cansaço rápido nas atividades físicas, dor nas costas com frequência, dor na musculatura do pescoço, diminuição de olfato ou paladar, halitose, sensação de boca seca, o indivíduo acaba acordando muito durante a noite engasgado, dorme mal, tem olheiras, espirra saliva ao falar e apresenta dificuldade para realizar exercícios físicos ${ }^{2}$. O respirador bucal apresenta como características: lábios entreabertos, língua no soalho bucal, hiperfunção do músculo mentual ao realizar o vedamento labial, lábio inferior com eversão por conta da retrusão da arcada inferior, problemas de oclusão dentária, palato atrésico e ogival, flacidez de bochechas e aumento da altura da face ${ }^{25}$.

Para compensar sua demanda respiratória, os atletas respiradores bucais tentarão respirar pela boca a fim de captar mais oxigênio. A falta desse vai alterar o seu metabolismo a ponto de apresentar dificuldades de recuperação de lesões musculares, problemas de visão e posturais, além de fadiga ${ }^{2}$.

$\mathrm{O}$ tratamento do atleta respirador bucal consiste em reeducação da musculatura oral; possibilitando postura adequada de lábios, língua e complexo maxilomandibular, adequação da mobilidade e motricidade, vedamento bucal, oclusão normal, aumento da capacidade pulmonar e automatização da respiração nasal ${ }^{6}$.

A atuação odontológica preventiva é indispensável para que patologias sejam identificadas. O cuidado com a cavidade bucal do esportista é fundamental, uma vez que, a presença de uma mastigação deficiente, causada por um foco dentário, falta de dentes, próteses desajustadas, inflamação de canal e/ou presença de cáries, possibilitam o surgimento de lesões. Sabe-se que a presença de um processo infeccioso no dente, quando não tratado corretamente pode originar desde uma alteração sanguínea até uma endocardite bacteriana8. Além disso, a mastigação inadequada provoca efeitos nocivos no aparelho gastrintestinal ${ }^{8}$.

A má oclusão dentária contribui para que uma mastigação deficiente se instale na cavidade oral, ocasionado prejuízos na absorção de nutrientes, impedindo a produção de energia imprescindível para ser empregada em treinamentos e competições, atrapalhando o desempenho esportivo ${ }^{5,26}$.

$\mathrm{O}$ rendimento físico de um atleta pode ser diminuído em $21 \%$ se houver a presença de alguma alteração na cavidade bucal, como por exemplo, má oclusão, anodontia, perda de dentes por avulsão durante a atividade esportiva, fomentando problemas na mastigação, nutrição ineficiente, consequentemente um menor aproveitamento energético ${ }^{24}$. 
Os fatores que levam ao aparecimento da má oclusão são hereditariedade; trauma no pré-natal, ao nascimento e pós-natal; extração precoce de dentes decíduos; deformidades no desenvolvimento; hábitos viciosos (chupar dedo, morder os lábios e língua, roer unhas, ranger os dentes); doenças sistêmicas e locais; distúrbios endócrinos e nutrição deficiente ${ }^{4}$.

O cirurgião-dentista pode oferecer melhorias no desempenho físico dos atletas por meio da manutenção da saúde bucal, prevenindo e tratando quaisquer $\mathrm{e}$ todas as mudanças no sistema estomatognático, como maloclusões dentais, que comprometem o desempenho dos atletas. Com o objetivo de investigar a presença de maloclusões dentais em atletas da categoria de 13 a 20 anos de idade do São Paulo Futebol Clube, Souza et al. ${ }^{27}$ realizaram um estudo. 84 atletas participaram da pesquisa. Os tópicos investigados foram: relação molar (classificação de Angle); presença de sobremordida ;submordida; apinhamento dental ; espaçamento anormal; mordida aberta; e mordida cruzada anterior; posterior; bilateral e unilateral; desvio da linha média e tipo facial (mesofacial, braquifacial e dolicofacial). Os resultados obtidos mostraram que, em relação à relação molar de Angle, $89 \%$ eram classe I, $8 \%$ classe II, 3\% classe III, 9\% dos atletas tinham sobremordida, 4\% tinham submordida, $13 \%$ tinham apinhamento dental e $21 \%$ tinham espaçamento anormal dos dentes. No que diz respeito à mordida, $11 \%$ apresentaram mordida aberta anterior. Em relação a mordia cruzada, 7\% apresentaram mordida cruzada unilateral direita e $2 \%$ esquerda; $5 \%$ apresentaram mordida cruzada posterior e $4 \%$ mordida cruzada anterior. Sobre o tópico desvios da linha media, 4\% apresentaram desvio na maxila e $33 \%$ na mandíbula. No que diz respeito ao tipo facial, $39 \%$ eram dolicofacial, $4 \%$ braquifacial e $57 \%$ mesofacial. Baseado nos achados desse estudo, propostas para implementação de clínicas: odontológicas, de fonoaudiologia e otorrinolaringologia estão sendo discutidas com a equipe multidisciplinar da equipe do clube em questão $^{27}$.

Em 2015, Ashley et al. ${ }^{28}$ publicaram estudo cujo objetivo era realizar revisão sistemática da epidemiologia de doenças bucais e trauma em na população de atletas de elite, investigando o impacto da saúde bucal no desempenho físico. Os autores utilizaram as bases de pesquisa MEDLINE (1950 a Outubro de 2013), EMBASE (1980 a Outubro de 2013), EBSCO SPORTDISCUS (a partir de Outubro de 2013) e OpenGrey. Nenhuma restrição de data ou lingua foi aplicada. Os artigos eram selecionados se avaliassem a saúde bucal de atletas profissionais. A qualidade metodológica dos artigos foi avaliada utilizando modificação da escala de NewcastleOttawa. Os resultados da pesquisa da literatura levaram a 9858 citações potencialmente relevantes.
Seguindo um critério de exclusão predefinido, 34 estudos foram mantidos. Vinte e seis estudos relataram trauma dental, com uma prevalência de $14 \%$ a $47 \%$, variando o esporte e o país. Dezesseis estudos consideraram a saúde bucal de atletas e relataram alta prevalência de doenças bucais: cáries dentais $15-75 \%$, erosão dental $36-85 \%$, doença periodontal $15 \%$. Em quatro estudos, $5 \%$ a $18 \%$ dos atletas relataram um impacto negative da saúde bucal e trauma em seu desempenho físico. A qualidade da metodologia dos estudos, geralmente era baixa. Os autores concluíram a saúde bucal dos atletas é pobre; e, supuseram que a saúde bucal está associada ao desempenho relatado, mas fazem a ressalva de que essa hipótese precisa ser testada, e concluem que, mais estudos devem ser realizados para apresentar o tamanho do problema de uma saúde bucal deficiente, assim como investigar seu possível impacto no desempenho físico dos atletas, utilizando medidas objetivas para a variável ${ }^{28}$.

Needleman et al. ${ }^{29}$ relatam que os poucos estudos que abordam a saúde bucal de atletas profissionais/ de elite de futebol, sugerem saúde bucal deficiente, com poucos dados dessa condição, e seu impacto no desempenho físico do atleta. Por essa razão, realizaram uma pesquisa com o objetivo de determinar a saúde oral em uma amostra representativa de jogadores profissionais de futebol do Reino Unido e investigar possíveis determinantes da saúde oral e o impacto reportado pelos próprios atletas em seu bem-estar, treinamento e desempenho. Foram realizados exames clínicos para verificar a saúde oral dos jogadores, esses exames foram conduzidos nas instalações do clube de treinamento. Dados de um questionário também foram coletados. 8 equipes foram incluídas, 5 da Liga Premier, 2 da Liga Championship, e 1 da Liga One. 6 cirurgiõesdentistas examinaram 187 jogadores que representaram $90 \%$ de cada equipe sênior. As análises mostraram que, a saúde bucal dos atletas é deficiente: $37 \%$ dos jogadores tinham cáries ativas, $53 \%$ erosão dental e 5\% doença periodontal irreversível, de moderada a severa. $45 \%$ estavam incomodados com sua saúde bucal, 20\% relataram impacto em sua qualidade de vida, e $7 \%$ em seu desempenho físico ou treino. Apesar dos atendimentos para avaliação odontológica, a saúde bucal se deteriorou com a idade. Os autores concluíram que a saúde bucal dos jogadores de futebol profissional é deficiente, e isso impacta em seu bem- estar e desempenho físico. Estratégias de sucesso para promover saúde bucal junto aos profissionais do futebol são de extrema necessidade, e as pesquisas devem investigar modelos baseados na melhor evidencia para a mudança no comportamento e implementação da ciência. Além disso, esse estudo fornece fortes evidências para suportar exames de saúde bucal em jogadores profissionais de futebol ${ }^{29}$. 
Outro aspecto frequentemente encontrado no meio esportivo é a utilização de isotônicos. Segundo Buischi $^{30}$, nos Estados Unidos, $36 \%$ dos nadadores e $85 \%$ dos ciclistas apresentavam erosão dentária, devido ao uso excessivo de isotônicos para reposição hídrica e eletrolítica durante a prática esportiva, sendo que o abandono do hábito é a única forma de prevenir essa lesão. Desta maneira, os esportistas que ingerem isotônicos mais de duas vezes ao dia possuem quatro vezes mais risco de adquirir alterações por erosão dental do que os que não consomem $^{2}$. Sendo assim, o atleta deve ingerir líquidos, de preferência água, antes, durante e após a atividade esportiva, mantendo a saúde equilibrada e bom desempenho físico ${ }^{2}$.

Além dos problemas já descritos, podem existir distúrbios na articulação temporomandibular por aumento de pressão sobre essa articulação, provocando dores de cabeça constantes, presença de zumbidos, tensão dos músculos frontal e temporal, seguidas ou não de fadiga de músculos mastigatórios ${ }^{24}$.

Os principais sinais e sintomas da disfunção da ATM são: dor na ATM, nos músculos da mastigação e tecidos adjacentes; crepitação ou estalos na ATM durante a abertura, fechamento da boca e limitação na abertura da boca e durante os movimentos de lateralidade e protrusão ${ }^{4}$.

A DTM pode ainda limitar as funções orais e causar problemas da fala, dificultar interações sociais, interferir na mastigação, na deglutição, na audição e nos fatores psicológicos dentre outras funções ${ }^{4}$. Portanto, necessita de diagnóstico preciso e tratamento multidisciplinar para que o atleta que sofre de disfunção temporomandibular faça as devidas cirurgias, fisioterapia e terapias oclusais, para que esse problema não interfira no seu rendimento no esporte ${ }^{4}$.

O acúmulo de bactérias na boca do atleta gera processos infecciosos que afetam diretamente seu rendimento, trazendo muitos problemas para sua saúde geral. Para evitar a ocorrência dessas infecções, o atleta deve manter higiene bucal adequada e ter consciência da importância de visitar o dentista periodicamente ${ }^{26}$. Pesquisas apontam que a cárie, por exemplo, é responsável pela perda de $17 \%$ do condicionamento do adolescente atleta ${ }^{24}$.

O principal fator que causa inflamação gengival é a presença de biofilme bacteriano cujos produtos vão iniciar uma cadeia de reação no tecido. Essa cadeia de reação vai levar a uma resposta do hospedeiro e ao processo destrutivo. A infecção bacteriana que atinge osso, gengiva e ligamento periodontal pode ser denominada como doença periodontal. As mais comuns são gengivite e periodontite, caracterizando processos inflamatórios nocivos. Na gengivite ocorre inflamação somente da gengiva e na periodontite, a inflamação é mais severa, pois ocorre perda da sustentação óssea ${ }^{26}$.

Existem diversas bactérias de infecções bucais que podem lesionar as articulações, criando problemas para o atleta, sem que ele saiba a origem ${ }^{2}$. Os processos infecciosos contribuem em muitos casos para o aparecimento de lesões musculoesqueléticas e alterações sanguíneas. As bactérias presentes na infecção bucal podem alcançar a corrente sanguínea e atacar os locais de compatibilidade estrutural. Algumas que se alojam em válvulas cardíacas, no endocárdio e endotélio, resultando em endocardite bacteriana ${ }^{26}$.

Deste modo, a alta prevalência de doenças bucais transforma a boca numa espécie de depósito de microrganismos capazes de provocar doenças cardíacas e vasculares ${ }^{3}$.

Além das cardíacas, a doença periodontal aumenta o risco para outras doenças sistêmicas como a diabetes mellitus. A inflamação crônica é um componente essencial para o desenvolvimento de aterosclerose e infecções respiratórias. Ademais, pneumonia bacteriana e bronquite têm sido associadas à doença periodontal por a aspiração de patógenos encontrados na cavidade oral e orofaríngea para as vias aéreas inferiores ${ }^{3}$.

Foco infeccioso na boca representa o comprometimento da saúde dos dentes (um canal aberto significa $17 \%$ de queda no condicionamento) e/ou do periodonto e de outros órgãos do corpo, espalhando-se através da corrente sanguínea, provocando risco para o coração, lesões nas articulações e dificuldade de recuperação em lesões musculares ${ }^{5}$. Portanto, é notório que o rendimento físico de uma pessoa que pratica esportes pode ser reduzido se ela tiver algum distúrbio na cavidade bucal. Os focos infecciosos, como cárie e doenças periodontais, atrapalham a mastigação e a respiração, interferindo também no rendimento físico ${ }^{24}$.

- Doping e a Odontologia do Esporte

De acordo com a Lei 5.081, de 24 de agosto de 1966, o profissional dentista tem o privilégio da prescrição medicamentosa a seus pacientes e sobre este aspecto o responsável pelo atleta deve assegurarse de que as drogas ministradas ou receitadas não provocarão o doping positivo, que é considerado pela Agência Mundial Antidopagem como contrário à essência do esporte ${ }^{31}$. Esta agência valoriza a ética, honestidade, saúde, excelência no rendimento, personalidade, educação, divertimento, satisfação, trabalho de equipe, dedicação e empenho, respeito pelas regras e pelas leis, respeito por si próprio e aos outros participantes, coragem, espírito de grupo e solidariedade. O cirurgião dentista não deve e nem pode ignorar que estes valores devem orientar a vida do atleta ${ }^{3}$.

O paciente atleta que está em tratamento odontológico deve ser medicado de forma diferenciada, levando em consideração a importância 
da prevenção do doping ante uma prescrição medicamentosa $^{32}$.

Dois tipos de controle antidoping são realizados em atletas pela Agência Mundial Antidoping. O primeiro deles é o controle em competição: realizado imediatamente após o término de uma competição esportiva. O segundo é o controle fora de competição: pode ser efetuado a qualquer momento, durante um treinamento, na residência do atleta, antes ou depois de uma competição. Ambos os métodos de controle são realizados com sangue e urina. Enquanto o exame em competição inclui todo o universo de classes de substâncias e de métodos proibidos, o exame fora de competição é mais específico. Drogas estimulantes, narcóticos analgésicos e drogas sociais não são analisados neste segundo tipo de controle ${ }^{32}$.

Uma terceira forma de controle é realizada momentos antes da competição. Esse controle é designado como controle de saúde. Realizado apenas com exame de sangue. $O$ resultado pode eventualmente excluir o atleta de uma prova sem que seja considerado como um controle positivo do uso de substâncias químicas para aumento do desempenho físico (doping) ${ }^{33}$.

Urina e sangue são as únicas matrizes autorizadas para testes antidopings pela Agência Mundial Antidoping. Potencialmente, a matriz de fluido bucal poderia complementar os testes antidoping no esporte, além de ser utilizada para monitorar programas de consumo de drogas no local de trabalho, toxicologia clínica, justiça criminal, e dirigir sob a influência de medicamentos. A coleta é fácil, não invasiva e neutra em relação ao sexo ${ }^{34}$.

Basicamente, duas substâncias utilizadas na Odontologia devem ser prescritas e ministradas com cautela: corticoides e anestésicos. Os corticosteroides estão indicados, na Odontologia, no controle de processos inflamatórios, tais como traumas póscirúrgicos, ulcerações bucais autoimunes, manifestações alérgicas graves (choque anafilático, edema de glote, broncoespasmo, rinite alérgica, dermatoses alérgicas, reações a fármacos), procedimentos endodônticos e artrite da articulação temporomandibular ${ }^{31}$. Anestésicos são permitidos como lidocaína, procaína, adrenalina entre outros, com exceção da cocaína. Mas a liberação só é permitida com a emissão de uma receita especificando dosagem e os motivos da recomendação ${ }^{31}$. Essas medicações não são consideradas substâncias proibidas e sim restritivas. Ambas devem ser citadas no formulário de Isenção de Uso Terapêutico (IUT) ${ }^{30}$.

De acordo com o Comitê Olímpico e Paralímpico, as substâncias proibidas são de uso controlado ou tem sua comercialização proibida dentro de um ou mais requisitos regulamentadores para proteger a saúde humana e/ou o meio ambiente.
São substâncias não aprovadas para uso, retiradas (ou em processo de retirada) do mercado interno pela indústria ou que passaram a ser desconsideradas em processos internacionais de aprovação; já as substâncias restritas são de uso limitado por regulamentações ou para as quais há dúvida científica razoável sobre sua adoção e riscos. Por razões de saúde e por indicação médica ou odontológica um atleta poderá necessitar de um medicamento que possua na sua formulação uma substância proibida ou restrita. Assim, é preciso solicitar uma permissão especial, que poderá ser concedida após a análise do diagnóstico e da indicação apropriada de um determinado medicamento. É indispensável o preenchimento do formulário de Isenção de Uso Terapêutico $^{33}$.

Cirurgiões-dentistas devem estar atentos aos efeitos adversos na cavidade bucal advindos das substâncias causadoras de doping. Dentre eles, destacam-se os derivados sintéticos da testosterona sobre os tecidos gengivais. Esteroide anabólico androgênico (EAA) é o nome familiar para a testosterona. Foi realizado um estudo com o intuito de avaliar os efeitos do uso abusivo do EEA sobre os tecidos gengivais em um grupo de fisiculturistas e levantadores de peso. Todos os atletas foram submetidos a exame clínico para os níveis de placa bacteriana e inflamação gengival. Os resultados dos estudos revelaram que o uso prolongado de EAA está intimamente associado com níveis significativos de hipertrofia gengival ${ }^{31}$.

DISCUSSÃO

A Odontologia do esporte é o campo responsável por prevenir, orientar e tratar os atletas de possíveis lesões provenientes da prática esportiva ${ }^{4}$. Desse modo, visa proporcionar uma excelente saúde bucal ao atleta, identificando condições prejudiciais ao mesmo 5 .

Os traumas bucofaciais aparecem frequentemente na prática esportiva. Os esportes de contato são importantes no que diz respeito aos traumatismos orofaciais e obtém-se destaque a prática de artes marciais, devido ao constante contato com a face ${ }^{12}$. Os índices de traumatismos em esportistas são altos, variando de acordo com o esporte praticado. Os esportes de grande contato físico, como as lutas, e os esportes coletivos, como o rúgbi e o futebol, são grandes colaboradores para aumento desses índices ${ }^{9}$.

Os traumatismos provocados pela atividade esportiva representam 14 a $39 \%$ das origens do trauma dentário e determinam o terceiro atendimento de traumas na face. Uma maneira de evitar ou reduzir os traumatismos seria a utilização de protetores bucais ${ }^{17}$. Estes são importantes, pois minimizam a ocorrência de lesões na região anterior da maxila, além de evitar injúrias na língua, lábios e face e 
diminuir os episódios de trauma na atividade esportiva ${ }^{6}$.

Os protetores confeccionados pelo dentista que são realizados a partir do modelo da arcada do atleta são os mais recomendados devido a excelente adaptação, conforto e por não interferirem na fala e na ingestão de líquidos durante as atividades esportivas. ${ }^{6}$ Entretanto a maioria dos atletas relata conhecer a importância do uso do protetor bucal, porém expõe que eles não estavam familiarizados com o risco de traumatismo orofacial durante a atividade esportiva. A maioria dos atletas faz uso de protetor bucal termoplástico, observando portanto a necessidade de maior difusão de conhecimento acerca das vantagens do protetor bucal personalizado e a promoção da motivação para o seu uso frequente durante as práticas esportivas. ${ }^{12}$

Uma pesquisa realizada para avaliar $o$ conhecimento de estudantes de graduação de odontologia e educação física sobre protetores bucais teve como conclusão que a maioria $(68 \%)$ dos alunos desconhecia os tipos de protetores bucais, porém sabia dos riscos corridos pelo atleta que pratica esportes de contato, o que demonstra a necessidade de maior divulgação quanto à utilização e importância dos protetores para os próprios estudantes ${ }^{13}$.

Os protetores faciais e nasais diminuem e distribuem as forças de impacto pela face. Estes, quando indicados e utilizados adequadamente, auxiliam no retorno do atleta aos treinos e competições. Como todos os equipamentos de proteção, em um primeiro momento, é recebido pelo atleta como um dificultador da sua atuação, entretanto é de responsabilidade do Cirurgião Dentista que o acompanha, explicar e orientar sobre a necessidade e importância do seu uso ${ }^{6,19}$.

A presença de bactérias na cavidade bucal predispõe a processos infecciosos bucais que são fundamentais para determinação do rendimento esportivo. Estes focos infecciosos quando não tratados podem levar a doenças cardíacas e vasculares $^{3,25}$. Diante disso, alguns autores propõem um protocolo para reabilitar um atleta, no qual a primeira fase visa eliminar os focos infecciosos da cavidade bucal, como cáries e doença periodontal, que contribuírem para o aparecimento de mediadores de inflamação na corrente sanguínea, que podem levar a doenças cardiovasculares diminuindo a qualidade de vida e comprometendo o rendimento esportivo ${ }^{3}$.

A doença periodontal é uma infecção limitada aos tecidos da gengiva que pode provocar sangramento, dor, edema e inflamação, podendo se alastrar pelos tecidos moles e atingir o osso alveolar, evoluindo assim de uma gengivite para uma periodontite. A doença periodontal é o quarto e último fator evidenciado por um estudo, que a correlacionou com as doenças sistêmicas, mas não como uma relação de causa e efeito, apenas coexistindo simultaneamente ${ }^{4}$.

Quando o atleta apresenta dor de dente, ele diminui sua capacidade de concentração e presença da dor leva os esportistas a respirarem por mais tempo pela boca9. A respiração bucal constitui um dos fatores responsáveis pela alteração do rendimento dos atletas, uma vez que diminui a capacidade aeróbica e facilita a propagação de processos infecciosos bucais para outros locais do corpo, como articulações e músculos ${ }^{2}$.

Os atletas que possuem dispneia irão tentar compensar sua demanda respiratória respirando pela boca para obter mais oxigênio, porém a falta de oxigênio vai mudar o metabolismo do atleta a ponto de apresentar dificuldades para se recuperar de lesões musculares, problemas de visão, posturais e fadiga. E pode influenciar na articulação temporomandibular (ATM) devido a elevada pressão que está sendo exercida sobre a mesma, o que gera zumbidos, dores de cabeças e tensão dos músculos frontal e temporal ${ }^{2,24}$.

Saúde bucal adequada oferece ao atleta condições ideais para o desenvolvimento de suas atividades, para isso a presença dos dentes e seu funcionamento correto durante o processo de mastigação são fundamentais. Qualquer alteração no sistema mastigatório pode levar a manifestação de enfermidades. A mastigação deficiente pode dificultar o processo digestivo, através de uma ineficaz absorção de nutrientes, prejudicando a produção de energia adequada para os atletas, consequentemente diminuindo seu rendimento ${ }^{8,26}$.

A Odontologia do esporte é diferente da tradicional porque o profissional especialista em esporte entende a cabeça do atleta. Um atleta que possui dor nas costas devido a um problema odontológico e o médico aborda como sendo de origem muscular, por exemplo, não tem o problema resolvido e ninguém consegue descobrir o porquê da não resolução. Este atleta tem seu tempo de recuperação aumentado em até duas vezes, devido ao seu sistema defensivo estar fragmentado entre se recuperar da lesão bucal ou da lesão física ${ }^{9}$.

Outra preocupação que o cirurgião-dentista especialista em esporte deve ter é a possibilidade da prescrição medicamentosa que cause doping positivo para um atleta em competição, portanto o dentista deve prescrever de forma diferenciada, levando em consideração os valores éticos de um competidor esportivo $^{3,31}$. A Agência Mundial Antidoping regulamenta a forma de detecção de substâncias que causam doping. Sendo exames de urina e sangue utilizados em testes de controle durante a competição e testes fora da competição ${ }^{33}$.

Substâncias proibidas e restritivas utilizadas no tratamento de um atleta devem ser notificadas por 
meio de um formulário de Isenção de Uso Terapêutico. Destas, as prescritas e ministradas por um cirurgião dentista são corticoides e anestésicos, ambas as substâncias restritivas. Embora não existam estudos comprovando o doping positivo por essas drogas o seu uso deve ser notificado ${ }^{30}$.

\section{CONCLUSÃO}

Em virtude dos aspectos observados sobre a Odontologia do esporte, percebe-se que ainda há carência de estudos sobre essa nova especialidade odontológica. Além disso, os cirurgiões dentistas e atletas possuem pouco conhecimento sobre essa prática preventiva e curativa. Portanto, é imprescindível maior divulgação e conscientização sobre a importância dessa especialidade, uso de protetores bucais personalizados e o quanto um foco infeccioso bucal e uma oclusão deficiente podem influenciar no desempenho do esportista; enfim, sobre o papel do dentista junto a uma equipe multidisciplinar para manter e melhorar a qualidade de vida dos atletas e consequentemente seu rendimento nas atividades esportivas.

\section{REFERÊNCIAS}

1. Padilha C, Namba EL, Coto NP. Qual o papel dos protetores bucais na redução da prevalência e da gravidade da concussão cerebral em esportes? Rev cir traumatol buco-maxilo-fac. 2014;14(3):73-8.

2. Vanz MP, Gehlen GLA, Rovani G, Conto F, Flores ME. Alteração do desempenho esportivo associado a causas bucais. In: Linden MSS, Carli JP, Magro ML, Trentin MS, Silva SO, organizadores. Odonto Science: 53 Anos FOUPF. São José dos Pinhas: Editora Plena; 2014. p.77-81.

3. Bastos RS, Vieira EMM, Simões CAD, Sales Peres SHC, Caldana ML, Lauris JRP et al. Odontologia desportiva: proposta de um protocolo de atenção à saúde bucal do atleta. RGO. 2013;61(Suppl 1):461-68.

4. Reinhel AF, Scherma AP, Peralta FS, Palma ICR. Saúde bucal e performance física de atletas. ClipeOdonto UNITAU 2013;7(1):45-56.

5. Sequeira E. Odontologia Desportiva: O Esporte e a Saúde Bucal. 2005. Disponível em:<http://www. saudetotal.com.br/artigos/saudebucal/odontodesp ortiva.asp> Acesso em: 26 de abril 2016.

6. Dias RB, Silva CMF, Gennari MG, Coto NP. Problemas Odontológicos $\mathrm{X}$ Rendimento Desportivo. Rev odontol Univ St Amaro. 2005;10(2):28-31.

7. Moura APF. Odontologia desportiva e o desempenho dos atletas. 2004. Disponível em: $<$ http://www.explorevale.com.br/2umatutino/mate rias/higiene_odontologia_esportiva.pdf > Acesso em: 10 de maio de 2016.

8. Rosa AF, Costa SB, Silva PRS, Roxo CDMN, Machado GS, Teixeira AAA, et al. Estudo descritivo de alterações odontológicas verificadas em 400 jogadores de futebol. Rev Bras Med Esporte. 1999; 5(2):55-8.

9. Lemos LFC, Oliveira RS. Odontologia desportiva. Uma breve revisão sobre essa nova tendência no esporte. Rev. Digital Educ Fis Deportes.2007; 12:1-5.

10. Santos V. Odontologia do Esporte. Odonto Magazine 2013; 3:18-20.

11. Yavich LG. Jornada Odontológica Interdisciplinar: Patologias da ATM e a sua conexão com a saúde integral do ser humano. 2016. Disponível em: <https://lidiayavi ch.com/tag/sintomatologia/> Acesso em: $10 \mathrm{de}$ abril de 2017.

12. Di Leone CCL, Barros IRCN, Salles AG, Antunes LAA, Antunes LS. O uso do protetor bucal nas artes marciais: consciência e atitude. Rev Bras Med Esporte. 2014;20(6):451-55.

13. Sizo SR, Silva ES, Rocha MPC, Klavtav EB. Avaliação do conhecimento em odontologia e educação física acerca dos protetores bucais. Rev Bras Med Esporte. 2009;15(4):282-86.

14. Souza JGS, Soares LA, Souza TCS, Pereira AR, Souza AGS. Traumatismos faciais decorrentes da prática esportiva. Rev bras cir cabeça pescoço. 2013;42(1):53-7.

15. Jerolimov V. Temporomandibular injuries and disorders in sport. Medical Sciences 2010;34:149-65.

16. Fonseca R. Trauma bucomaxilofacial. $4^{\text {a }}$. ed. Rio de Janeiro: Elsevier; 2015.

17. Costa SS. Odontologia desportiva na luta de reconhecimento. Rev Odontol Univ Cidade de São Paulo. 2009;21(2):162-68.

18. Lopes LBPM, Ferreira JF. Dental trauma in contact sports. RGO. 2017;65(3):237-42.

19. Coto NP, Meira JB, Brito e Dias R, Driemeier L, de Oliveira Roveri G, Noritomi PY. Assessment of nose protector for sport activities: finite element analysis. Dent Traumatol. 2012;28(2):108-13.

20. Mcintosh L, Cordell JM, Johnson AJW. Impact of bone geometry on effective properties of bone scaffolds. Acta Biomater 2009;5(2):680-92.

21. Westerman B, Stringfellow PM, Eccleston JA, Harbrow DJ. Effect of ethylene vinyl acetate (EVA) closed cell foam on trasmitted forces in mouthguard material. $\mathrm{Br} \mathrm{J}$ Sports Med. 2002;36(3):205-8.

22. Goiato MC, Santos DM, Moreno A, Haddad MF, Pesqueira A A, Turcio KHL, Dekon SFC et al. Use of facial protection to prevent reinjury during sports practice. J Craniofacial Surg. 2012;23(4):1201-2.

23. Anjos DSC, Sá FC, Azevedo EN, Revoredo ECV, Galembeck A. Blendas de silicone-acrilato para 
próteses faciais. Anais - Natal: Sociedade Latina Americana de Biomateriais, Orgãos Artificias e Engenharia de Tecidos, 2012.

24. Antunez MEM, Reis YB. O binômio esporte odontologia. Rev Adolesc Saúde. 2010;7(1):37-9.

25. Nishimura CM, Gimenez SRML. Perfil da fala do respirador oral. Rev CEFAC. 2010;12(3):36- 9.

26. Leite JVM, Feitosa GM, Souza FASP, Pedrosa JCP, Antunes LL, Bezerra R. Odontologia Desportiva x performance física. 2007. Disponível em: <http://worldsoccerone.blogspot.com.br/ search/label/Odontologia\%20Desporti va> Acesso em: 26 de abril de 2016.

27. Souza LA, Elmadjian TR, Dias RB, Coto NP. Prevalence of malocclusions in the 13-20 year old categories of football athletes. Braz Oral Res. 2011;25(1):19-22.

28. Ashley P, Di Iorio A, Cole E, Tanday A, Needleman I. Oral health of elite athletes and association with performance: a systematic review. Br J Sports Med. 2015;49(1):14-9.

29. Needleman I, Ashley P, Meehan L, Petrie A, Weiler R, McNally $\mathrm{S}$ et al. Poor oral health including active caries in 187 UK professional male football players: clinical dental examination performed by dentists. $\mathrm{Br} \mathrm{J}$ Sports Med. 2016;50(1):41-4.

30. Buischi Y. Bebidas e alimentos que causam erosão dentária. 2004. Disponível em: <http://odontologia.com.br.asp/?id=366idesp=1\&l er=s> 22 mar 2004.

31. Ranalli D. Adolescent athletes: perspectives for dental practitioners. Northwest Dentistry. 2007:15-20.

32. Mello AB, Flório FM. Odontologia do esporte: como atuar em equipe na prescrição segura de medicamentos? FIEP Bulletin 2010; 80, Special Edition, Article II, disponível em http://www.fiepbulletin.net.

33. Rose EH, NETO FRA, Levy R. Informações sobre o uso de medicamentos no esporte. 2006. Disponível em: http://www.cbh.org.br/arquivos/ Informacoes $\% 20$ sobre $\% 20 \mathrm{o} \% 20$ uso $\% 20 \mathrm{de} \% 20 \mathrm{~m}$ edicamentos $\% 20$ no $\% 20$

Esporte\%20\%20COB\%20Cavaleiros\%20Amazon as.pdf > Acesso em: 10 de abril de 2017.

34. Anizan S, Huestis MA. The potential role of oral fluid in antidoping testing. Clin Chem. 2014; 60(2):307-22.

\section{CONFLITO DE INTERESSES}

Os autores declaram não haver conflitos de interesse.

AUTOR PARA CORRESPONDENCIA

Marcela Filié Haddad

marcela.haddad@unifal-mg.edu.br

Submetido em 11/03/2019

Aceito em 11/06/2019 